\title{
Planejamento e Políticas Públicas do Turismo: uma discussão teórica no contexto das Unidades de Conservação do Brasil
}

\author{
Planning and Public Policies of Tourism: a theoretical discussion in the context \\ of Protected Areas of Brazil
}

\section{Iracy Wanderley Filha, Francisco Fransualdo de Azevedo, Wilker Ricardo de Mendonça Nóbrega, Jaci Câmara de Albuquerque}

\section{RESUMO}

O processo de planejamento e gestão em áreas naturais tem ocupado um lugar de destaque nas discussões acadêmicas e governamentais, no sentido do uso destas áreas como opções de lazer e contemplação de grupos de turistas interessados em relacionar-se com a natureza. Este estudo tem como objetivo discutir as estratégias de planejamento e gestão do turismo em Unidades de Conservação (UC's). Para isso, foi adotada uma abordagem qualitativa, sob uma perspectiva crítica, através de uma pesquisa bibliográfica, documental, e em meios digitais, acerca de temas como planejamento, gestão, políticas públicas, Estado, desenvolvimento sustentável e turismo. No que concerne à identificação das estratégias do planejamento e da gestão do turismo nas UC's brasileiras, estas foram examinadas a partir das categorias estabelecidas pela Lei Federal № 9.985 de 18 de julho de 2000, que instituiu o Sistema Nacional de Unidades de Conservação (SNUC), bem como através das diretrizes estabelecidas pelo Ministério do Turismo (Mtur) através do Plano Nacional do Turismo (PNT). Os principais resultados e reflexões deste trabalho apontaram que, os estados e municípios brasileiros, na sua maioria, não dispõem de infraestrutura necessária para a efetiva implantação do turismo em UC's, isto é, de modo que os recursos estruturais possibilitem a consolidação das funções socioambientais, econômicas e culturais do ecoturismo. Em se tratando do PNT, os resultados também revelaram que no Macro Programa 4, de estruturação e diversificação da oferta turística, há referência à segmentação do mercado porém, este não evidencia quais segmentos serão trabalhados prioritariamente, muito menos como devem ser geridos. O estudo buscou despertar a necessidade de ampliar e aprofundar debates sobre o planejamento e gestão do turismo em UC's no sentido de promover as condições técnicas e infraestruturais necessárias para implementação do segmento ecoturístico.

PALAVRAS-CHAVE: Turismo; Planejamento; Política Pública de turismo; Unidades de Conservação; Desenvolvimento. 


\begin{abstract}
The process of planning and management in natural areas has become an important focus in academic and political discussions with respect to the use of these areas for leisure and enjoyment by groups of tourists interested in being in touch with nature. The primary objective of this study is to discuss tourism planning and management strategies in conservation units (Unidades de Conservação -UC's). To that end, we adopted a qualitative approach with a critical perspective that included a literature review, and a review of documents and digital media related to topics such as planning, management, public policy, the state, sustainable development and tourism. With respect to identifying tourism planning and management strategies in Brazilian UCs, we examined them according to the categories established by Federal Law number 9.985 of July 18, 2000, which instituted the National System of Conservation Units (Sistema Nacional de Unidades de Conservação - SNUC) as well as through the guidelines established by the Ministry of Tourism (Mtur) through their National Tourism Plan (Plano Nacional de Turismo - PNT). The main results and reflections of this study indicate that, in general, Brazilian states and municipalities do not have the necessary infrastructure to effectively implement tourism in (UC's), i.e., in a way that the structural resources facilitate consolidation of the socio-environmental, economic, and cultural functions of tourism. In terms of PNT, the results also revealed that in the Macro Program 4, which contemplates the structuring and diversification of tourism supply, there is reference to market segmentation however, there is no mention of which segments will be given priority and even less mention of how these will be generated. Our study sought to awaken the need to broaden and deepen debates related to tourism planning and management in (UC's) with respect to promoting the necessary technical and infrastructural conditions to implement ecotourism.
\end{abstract}

KEYWORDS: Tourism; Planning; Tourism Policies; Conservation Units; Development.

\title{
Introdução
}

No decorrer da história da humanidade, as relações das diferentes sociedades com o espaço natural tem provocado a perda da biodiversidade face à degradação ambiental imposta pela sociedade como a desterritorialização das espécies da flora e fauna, em alguns casos, por meio da relação imperiosa do consumo do espaço natural pela atividade turística. Este processo de degradação tem influenciado o surgimento de diversos estudos científicos e discussões globais na busca de estratégias adequadas para mitigar ou melhorar o que foi estabelecido como problemática ambiental.

Este estudo tem o objetivo de discutir as estratégias de planejamento e gestão do turismo em Unidades de Conservação (UCs) direcionando uma apreciação crítica para o Sistema Nacional de Unidades de Conservação brasileiro numa interface com o "Plano Nacional do Turismo - Diretrizes, Metas e Programas 2003-2007" (PNT, 2003).

A metodologia utilizada para a realização deste estudo abordou, qualitativamente, sob uma perspectiva crítica, a pesquisa bibliográfica, documental e em meios digitais, acerca do planejamento, gestão, políticas públicas, Estado, desenvolvimento sustentável e turismo. 
Para identificar as estratégias do planejamento e da gestão do turismo nas Unidades de Conservação brasileiras, esta pesquisa procurou examiná-las frente às categorias estabelecidas pela Lei Federal № 9.985 de 18 de julho de 2000, que institui o Sistema Nacional de Unidades de Conservação - SNUC (ver Quadro 1 adiante), as diretrizes do Plano Nacional do Turismo (PNT) para o turismo e suas correlações com o aporte teórico.

Considerando as normas constituídas pelo SNUC (Lei Federal № 9.985/00), no Brasil foram instituídos 02 (dois) grupos de UCs: a) Unidades de Proteção Integral e b) Unidades de Uso Sustentável, subdivididos em 12 (doze) categorias específicas. A gestão do SNUC é feita com a participação das três instâncias de governança do poder público (federal, estadual e municipal). Analisando as conformidades legais do SNUC é possível perceber a visão estratégica que este propõe aos tomadores de decisão de modo que possibilitem aos atores das UCs, além de conservar os ecossistemas e a biodiversidade, gerar renda, emprego, desenvolvimento e propiciar uma efetiva melhoria na qualidade de vida das populações locais e do Brasil como um todo.

A participação do governo no planejamento e na gestão pública do turismo e de Unidades de Conservação é assegurada quando da criação de órgãos consultivos, instrumentos legais, programas, projetos, políticas públicas e de espaços de participação popular. Nesta perspectiva, o Plano Nacional de Turismo (PNT) 2003-2007 está estruturado em Macro Programas, Programas e Ações advindas dos seus objetivos gerais e específicos na área do turismo. Estes assimilam a noção do território como espaço e lugar de interação do homem com o ambiente, dando origem a diversas maneiras de se organizar e se relacionar com a natureza, com a cultura e com os recursos de que dispõe. Essa noção supõe formas de coordenação entre organizações sociais, agentes econômicos e representantes políticos, superando a visão estritamente setorial do desenvolvimento.

As instituições políticas, numa palavra o Estado, na sua capacidade de desenvolver o sistema político, ao criar instrumentos legais e políticas públicas precisam cumprir a sua função que é a de dar respostas às demandas procedentes do ambiente social. Porém, os principais resultados evidenciam que, os Estados e Municípios brasileiros, na sua maioria, não dispõem de infraestrutura necessária à efetiva implantação do turismo em unidades de conservação como recursos humanos e financeiros, capacidade administrativa, elaboração e execução de Planos de Manejo e Zoneamento Econômico-Ecológico. Nesse sentido, estão sujeitas a prováveis impactos negativos no meio ambiente podendo não atingir seus objetivos, previstos em lei, de conservação e bem estar da população.

\section{Planejamento Turístico X Espaço: a relação com o Estado}

Hodiernamente a atividade turística tem apresentado um forte crescimento no cenário internacional e se constituído uma das atividades econômicas mais importantes do mundo. De acordo com Cruz (1999, p.2): 
[...] as estatísticas oficiais mostram ainda que a atividade turística revela números expressivos, também, no que se refere a deslocamentos de fluxos, à mão de obra empregada na atividade, na geração de renda etc.

A Organização Mundial de Turismo (2003) compreende o turismo como "as atividades que as pessoas realizam durante viagens e estadas em lugares diferentes do seu entorno habitual, por um período inferior a um ano, com a finalidade de lazer, negócios ou outras". Assim, de acordo com Dias (2011, p.4):

O turismo é considerado hoje como a atividade econômica mais importante do mundo em alguns países, regiões e localidades e constitui um fator determinante nos rumos do desenvolvimento. Podemos identificálo como um fenômeno que apresenta várias faces - social, geográfica, econômica, cultural, ambiental - destacando-se em todas elas como uma força que provoca mudanças, em rápidos processos de transformação.

Por esse contexto é perceptível o fato do turismo interferir significativamente na organização do espaço geográfico ${ }^{1} \mathrm{e}$, enquanto prática social, à medida que se apropria desse espaço ele o consome e (re)produz. O turismo que, antes de tudo, é uma prática social vem mudando de sentido ao longo da história e cada nova definição consiste em uma nova tentativa de se conceituar algo que tem, reconhecidamente, uma dinâmica irrefutável (CRUZ, 2003). Parece claro afirmar que, ao longo da história, as civilizações em seus distintos modos de organização espacial interferem no espaço seja pelo trabalho - através da técnica, seja pela definição cultural. Como afirma Soares (2001, p. 44),

O ponto central dessas ações de interferências está no espaço geográfico, que por sua vez, figura-se como resultado da interação contínua e indissociável entre sistemas de objetos ${ }^{2}$ e sistemas de ações.

Numa análise estrutural, é possível afirmar que as civilizações ora mencionadas produzem o espaço geográfico inter-relacionando causas e consequências, o todo e as partes em sua complexidade e totalidade dinâmica.

Desta feita, convém ressaltar que na atividade turística estão contidas várias formas de inter-relações que atribuem valor e sentido ao espaço geográfico. Através desta atividade utilizam-se tanto os objetos naturais (Ex. as dunas, falésias, cachoeiras, praias, vegetação, rios, montanhas) para visitação, como também os objetos artificiais para atendimento ao público, como é o caso das estradas, restaurantes, hotéis, transporte e outros serviços.

Nessa perspectiva analítica, Nascimento (2008, p. 27) apud Santos (1985) as- 
segura que:

O espaço deve ser analisado a partir de quatro categorias as quais devem ser consideradas em suas relações dialéticas, são elas: estrutura, processo, função e forma. A forma é o aspecto visível, arranjo de um ou um conjunto de objetos, formando um padrão espacial (equipamentos turísticos, por exemplo) ${ }^{3}$; a função indica o papel a ser desempenhado pelo objeto criado, o lazer e o trabalho, constituem algumas das funções associadas aos equipamentos turísticos.

A estrutura é outra categoria de análise do espaço que está relacionada diretamente à natureza social e econômica de uma sociedade ${ }^{4}$ num determinado momento temporal. Numa tentativa de inserção da forma e da função na estrutura social é possível captar a natureza histórica do espaço (NASCIMENTO, 2008). Ao pensarmos a relação turismo e espaço entendemos que a prática social da atividade turística "consome" o espaço geográfico no momento em que se apropria deste introduzindo objetos que podem contribuir com o seu desenvolvimento e/ou incorporaram outros já existentes acarretando mudanças parciais ou totais em suas funções. O espaço turístico é, antes de tudo, um espaço geográfico e, portanto, constitui um produto social em permanente processo de transformação (SANTOS, 1985).

São necessários procedimentos e tarefas que se atenham a todas as interrelações e consequências do consumo do espaço pelo turismo, de modo que haja benefícios para o ambiente heterogêneo e dinâmico dos sistemas ecológicos, econômicos e sociais que o compõem. Nesse sentido, presume-se que, para a consolidação das funções socioambientais relativas ao desenvolvimento da atividade turística fazse necessário que a sociedade programe estratégias de planejamento que garantam a participação dos múltiplos atores sociais neste processo. Para Cruz (2006, p. 342):

O planejamento é algo que remete sempre ao futuro, já que não se pode planejar o passado ou o presente. Planejar significa, sempre, projetar o futuro que se deseja. Cruz ainda divide o planejamento em três 4 momentos: é preciso olhar para o passado e identificar os erros que não se deseja voltar a cometer, diagnosticando o presente, e daí pensar os cenários futuros, em segundo lugar diz que o planejamento é meio e não o fim, sendo um processo político-ideológico que exprime anseios, objetivos e visões de mundo dos atores sociais que o conduzem. Em terceiro lugar que é o planejamento é um processo, e por isso comporta uma gama de ações (a organização social de um dado setor como da vida social - e este caso o turismo- somente pode resultar de um processo contínuo de planejamento e, finalizando diz que planejamento local e regional não são necessariamente excludentes, ou se já o planejamento regional não elimina a possibilidade de existência de planejamento de escala local, desde que, naturalmente, estes sejam convergentes. Tais processos de planejamento envolvem , também a elaboração de políticas públicas. 
Assim sendo, há que se pensar num planejamento qualitativo do turismo de modo que este tenha como objetivo a conservação do espaço natural, da cultura regional e o desenvolvimento socioeconômico das pessoas do espaço onde se estabelece. Por sua vez, tal processo, para minimizar os impactos socioambientais e culturais inerentes à atividade turística precisa se basear na pesquisa e avaliação que busca sugerir a otimização do potencial de contribuição ao bem estar do ser humano e ao meio ambiente (HALL, 2001; OMT, 2003).

A capacidade de os indivíduos e grupos participarem no sistema de planejamento turístico se configura como condição sine qua non na tomada de decisões e elaboração de políticas públicas. Tais decisões são interdependentes ou sistematicamente relacionadas e não seriam decisões individuais. $O$ fato é que a participação não é somente o resultado de valores culturais ou democráticos, mas também produto das estruturas do governo público e do grau em que essas estruturas são verdadeiramente abertas à participação e ao debate.

De modo similar, cabe verificar a possível atuação dos agentes políticos em exercerem suas responsabilidades na criação e implementação de políticas públicas na configuração do turismo no espaço geográfico. Nesse contexto, Bobbio (1986, p. 95) afirma que:

\begin{abstract}
Do ponto de vista de uma definição formal e instrumental, condição necessária e suficiente para que exista um Estado é que sobre um determinado território se tenha formado um poder em condição de tomar decisões e emanar os comandos correspondentes, vinculatórios para todos aqueles que vivem naquele território e efetivamente cumpridos pela grande maioria dos destinatários na maior parte dos casos em que a obediência é requisitada. Sejam quais forem às decisões.
\end{abstract}

Pela afirmativa supracitada, as instituições políticas, numa palavra o Estado, na sua capacidade de desenvolver o sistema político, por sua vez precisam responder às demandas sociais para cumprirem a sua função. Planejar é, portanto, apenas uma parte de um processo global de "planejamento-decisão-ação". O pensador italiano Bobbio (1986) destaca duas características distintivas da atuação estatal. A universalidade, onde o Estado toma decisões em nome de toda a coletividade que ele representa, e não apenas da parte que exerce o poder; e a inclusividade que em princípio, nenhuma esfera da vida social encontra-se fora do alcance da intervenção do Estado. Isso, no entanto, não significa que o Estado tenha de intervir ou regular tudo - apenas os Estados totalitários têm essa pretensão -, mas que é prerrogativa do Estado definir as áreas em que irá ou não intervir, conforme o tempo, as circunstâncias e o interesse público.

Por essa análise, o Estado, para atender às reivindicações da sociedade toma decisões sem gerar novos conflitos com os atores sociais. Isto é política, ou seja: politics. Já o termo policy faz referência à formulação de propostas, tomada de decisões e sua implementação por instituições políticas, evidenciando temas de foco coletivo, 
mobilizando interesses e conflitos. Em outras palavras, policy significa a atividade do governo de desenvolver políticas públicas, a partir do processo da política (RUA, 2009). No Quadro 1 é possível ter clarificado as diferenças entre política pública e decisão política.

Quadro 1: Diferença entre política pública e decisão política.

Table 1: Difference between public policy and political decision.

\begin{tabular}{|l|l|}
\hline \multicolumn{1}{|c|}{ Política pública } & \multicolumn{1}{c|}{ Decisão política } \\
\hline $\begin{array}{l}\text { Geralmente envolve mais do que uma deci- } \\
\text { são e requer diversas ações estrategica- } \\
\text { mente selecionadas para }\end{array}$ & $\begin{array}{l}\text { Corresponde a uma escolha dentre um con- } \\
\text { junto de possíveis alternativas, conforme a } \\
\text { implementar as decisões tomadas. }\end{array}$ \\
$\begin{array}{l}\text { volvidos, expressando - em maior ou menor } \\
\text { grau - uma certa adequação entre os fins } \\
\text { pretendidos e os meios disponíveis. }\end{array}$ \\
\hline
\end{tabular}

Fonte: Adaptado de Rua (2009, p.9).

Source: Adapted from Rua (2009, p.9).

Por esse entendimento, embora uma política pública implique decisão política, nem toda decisão política chega a constituir uma política pública ${ }^{5}$ (RUA, 2009). É importante ressaltar que esta consiste na resolução pacífica de conflitos sociais imprescindíveis à preservação da vida em sociedade. Dada à relevância de se entender o seu significado no contexto deste estudo, é pertinente entendê-la como tudo que as instâncias de governança do Estado (federal, estadual e municipal) fazem ou o que não fazem, já que, o fato de não haver ação reflete o baixo nível de valor agregado a determinados temas ligados ao contexto em tela. Para aprofundar ainda mais o entendimento conceitual acerca do termo política pública destacamos a concepção segundo a qual esta se caracteriza como:

O conjunto de ações coletivas voltadas para a garantia dos direitos sociais, configurando um compromisso público que visa dar conta de determinada demanda em diversas áreas. Expressa a transformação daquilo que é do âmbito privado em ações coletivas no espaço público (SANTOS, 2012, p.117 apud GUARESCHI, 2003).

Sendo a política pública para o turismo tudo o que os governos decidem fazer ou não com relação a esse setor, o planejamento turístico, tem como objetivo geral promover o desenvolvimento da atividade turística setorial de modo que esta tenha condições de ampliar gradualmente sua atuação, minimizando seus efeitos negativos e potencializando os resultados desejados pela demanda coletiva.

Recentemente os governos tem se envolvido cada vez mais na divulgação e no marketing dos destinos, e no desenvolvimento conjunto de atrações ou instalações 
turísticas com o setor privado. Como afirma Petrocchi (1999) o turismo receptivo é um dos alvos da política governamental para os próximos anos. O país já reconhece que as ações implementadas pelas atividades turísticas podem desencadear oportunidades econômicas superiores a qualquer outro setor. No entanto, é preciso atentar para métodos de planejamento turístico que considerem a necessidades de infraestrutura, o uso adequado do solo e de recursos (naturais e culturais), a qualificação profissional dos atores, a divulgação e o marketing e a garantia de participação de todas as estruturas sociais.

\title{
O Planejamento governamental turístico no âmbito das Unidades de Conserva- ção (UCs): uma aproximação com o desenvolvimento sustentável
}

É clara a compreensão de que, sendo os elementos do espaço (meio físico, social e cultural) a "matéria-prima" da atividade turística, sua inter-relação com o meio ambiente é incontestável. O turismo, nas suas formas de "consumir" o espaço, estabelece uma relação "comensal" quando o aproveita de forma apropriada e satisfatória, contribuindo ou não nas questões naturais. No entanto, quando estabelece uma relação predatória com o espaço geográfico pode descaracterizar sistemas ecológicos e socioculturais essenciais ao equilíbrio e manutenção da vida na Terra. Para Ansarah (2001, p. 30):

\begin{abstract}
O estudo do turismo deve ser direcionado para o desenvolvimento sustentável, conceito essencial para alcançar metas de desenvolvimento Sem esgotar os recursos naturais e culturais nem deteriorar o meio ambiente, entende-se que a proteção do meio ambiente e o êxito do desenvolvimento turístico são inseparáveis.
\end{abstract}

Furtado (2000, p. 22), explora o conceito de desenvolvimento atribuindo a este basicamente duas dimensões, existindo ainda uma terceira que, segundo o autor, seria menos explícita. A primeira dimensão, em síntese, estaria relacionada ao incremento da eficácia do sistema social de produção, a segunda na satisfação das necessidades básicas humanas e a terceira na consecução dos objetivos a que almejam grupos dominantes de uma sociedade e que competem na utilização dos recursos escassos. Para o autor, essa terceira dimensão seria a mais ambígua de todas, chegando a ser percebida apenas no discurso ideológico, concluindo que:

[...] a concepção de desenvolvimento de uma sociedade não é alheia a sua estrutura social, e tampouco a formulação de uma política de desenvolvimento e sua implantação são concebíveis sem preparação ideológica (FURTADO, 2000, p.22).

Apesar dessa noção de desenvolvimento não se pode, contudo, atrelar a ideia de desenvolvimento diretamente à questão do crescimento econômico, mas sim, nu- 
ma das condicionantes desse processo e não somente a única das questões nele envolvidas. Nesse sentido, o crescimento econômico, situado na questão do aumento da eficácia de produção, segundo Furtado (1974, p.22), não teria condição suficiente para indicar se determinado local é ou não desenvolvido, assim ele esclarece:

\begin{abstract}
O aumento da eficácia do sistema de produção - comumente apresentada como indicador principal do desenvolvimento - não é condição suficiente para que sejam mais bem satisfeitas as necessidades elementares da população. Tem-se mesmo observado a degradação das condições de vida de uma massa populacional como consequência da introdução de técnicas mais sofisticadas. Por outro lado, o aumento da disponibilidade de recursos e a elevação dos padrões de vida podem ocorrer na ausência de modificação nos processos; por exemplo, quando aumenta a pressão sobre as reservas de recursos não reprodutíveis (FURTADO, 1974, p.22).
\end{abstract}

Para Sachs (2004, p.15), a sustentabilidade tem como base cinco dimensões principais que são: a sustentabilidade social, ambiental, territorial, econômica e política. Este mesmo autor acrescenta mais duas dimensões ou critérios de sustentabilidade: cultural e ecológica, significando:

\begin{abstract}
Um processo de transformação no qual a exploração dos recursos, a direção dos investimentos, a orientação do desenvolvimento tecnológico e a mudança institucional se harmonizam e reforçam o potencial presente e futuro, a fim de atender às necessidades e aspirações humanas.
\end{abstract}

A Organização Mundial do Turismo (OMT, 2003) entende que o turismo sustentável e seguro deve levar em consideração todos os aspectos da diversidade cultural e institucional, privilegiando aspectos físicos e ambientais capazes de influenciar diretamente nas condições de saúde, qualidade de vida e segurança das pessoas e comunidades. Foi nesse cenário que surgiu a necessidade de se trazer a dimensão ambiental para a dinâmica do desenvolvimento da atividade turística. De acordo com a IUCN, a criação de UCs é à medida que melhor exemplifica, na atualidade, a tentativa de preservar os recursos naturais e a vida dos diversos ecossistemas nessas áreas protegidas sendo que, seus princípios devem ir além das questões ecológicas, já que compreende também a melhoria das condições econômicas e sociais das populações locais, além da satisfação dos visitantes do destino.

Visando disciplinar o uso de áreas protegidas, o governo brasileiro aprovou em 2000, a Lei Federal № 9.985, que institui o Sistema Nacional de Unidades de Conservação - SNUC. Esta Lei estabelece critérios e normatizações para criação, implantação e gestão de Unidades de Conservação - UCs. De acordo com a referida Lei, Unidades de Conservação são entendidas como: 
Espaços territoriais e seus componentes, incluindo as águas jurisdicionais, com características naturais relevantes, de domínio público ou privado, legalmente instituídos pelo Poder Público, com objetivos de conservação e de limites definidos, sob regime especial de administração, às quais se aplicam garantias adequadas de proteção (SNUC, Lei № 9.985/00, Art. $2^{\circ}$ )

Considerando as normas constituídas pelo SNUC (Lei Federal № 9.985/00), no Brasil foram instituídos 02 (dois) grupos de UCs: a) Unidades de Proteção Integral e b) Unidades de Uso Sustentável, subdivididos em 12 (doze) categorias especificadas conforme o Quadro 2:

Quadro 2: Grupos de Unidades de Conservação e suas categorias de manejo.

Table 2: Groups of Protect Areas and their management categories.

\begin{tabular}{|c|c|}
\hline UNIDADES DE PROTEÇÃO INTEGRAL & UNIDADES DE USO SUSTENTÁVEL \\
\hline Estação Ecológica (ESEC) & Área de Proteção Ambiental (APA) \\
\hline Reserva Biológica (REBIO) & $\begin{array}{c}\text { Área de Relevante Interesse Ecológico } \\
\text { (ARIE) }\end{array}$ \\
\hline Parque Nacional (PARNA) & Floresta Nacional (FLONA) \\
\hline Monumento Natural & Reserva Extrativista (RESEX) \\
\hline Refúgio da Vida Silvestre & Reserva de Fauna \\
\hline & $\begin{array}{c}\text { Reserva de Desenvolvimento Sustentável } \\
\text { (RDS) }\end{array}$ \\
\cline { 2 - 2 } & $\begin{array}{c}\text { Reserva Particular do Patrimônio Natural } \\
\text { (RPPN) }\end{array}$ \\
\hline
\end{tabular}

Fonte: Brasil (2000).

Source: Brasil (2000).

De acordo com a Lei Federal 9.985/00, o SNUC é gerido pelos seguintes órgãos, com as respectivas atribuições: Órgão consultivo e deliberativo: representado pelo Conselho Nacional do Meio Ambiente (CONAMA), tem a função de acompanhar a implementação do SNUC; Órgão central: representado pelo Ministério do Meio Ambiente, tem a finalidade de coordenar o SNUC; Órgãos executores: representados na esfera federal, pelo Instituto Chico Mendes de Conservação da Biodiversidade (ICMBio) e IBAMA (Instituto Brasileiro do Meio Ambiente e dos Recursos), em caráter supletivo, e nas esferas estadual e municipal, pelos órgãos estaduais e municipais de meio ambiente. Ainda de acordo com a referida Lei, os órgãos executores do SNUC têm a função de implementá-lo, subsidiar as propostas de criação e administrar as unidades de conservação federais, estaduais e municipais mas, nas respectivas esferas de atuação. As competências dos órgãos para a gestão do sistema vão desde a coordenação e acompanhamento até a sua implementação propriamente dita. 
Diante da necessidade de se manter a integridade das UCs, cumpre frisar, de uma forma ímpar, que a atividade turística para se estabelecer nesses espaços naturais legalmente protegidos, precisa levar em consideração a relação entre as pessoas, suas atividades e o uso que fazem do espaço que as envolve, com respeito aos limites dos sistemas ecológicos e dos sistemas socioculturais. Nesse contexto o ecoturismo é, segundo as "Diretrizes para a Política Nacional de Ecoturismo",

Um segmento da atividade turística que utiliza de forma sustentável o patrimônio natural e cultural, incentiva sua conservação e busca a formação de uma consciência ambientalista através da interpretação do ambiente, promovendo o bem-estar das populações envolvidas (BRASIL, 1994, p.19).

No entanto Soares (2011, p.41 apud PIRES et al. 2002, p.126) diz que "há controvérsias sobre a correta utilização da terminologia e a interpretação de seu significado". E ainda afirma que "muitas vezes, é nele que os conflitos e problemas gerados na dinâmica dos acontecimentos e na profusão de realidades que os envolve vão desembocar".

No universo analítico sobre o significado de ecoturismo, são utilizados diversos termos, como "turismo de natureza", "turismo responsável", "turismo verde", "turismo ecológico", "turismo ambiental", "turismo sustentável", e estes se apresentam de formas semelhantes e até mesmo idênticas. Por isso, a opção do ecoturismo pela prática em Áreas Naturais Protegidas (ANPs), torna-o "considerado por alguns autores um tipo especial de turismo na natureza" (SOARES, 2011 apud PIRES, 2002, p.126).

De acordo com a conceituação de ecoturismo, cabe frisar que, há uma clara demonstração de que, nesse tipo de atividade deve ser priorizada a harmonia entre as componentes ecológicas e dos valores culturais sistemicamente inseridos nas UCs. Sendo assim há uma oportunidade para se promover uma consciência ecológica e a conservação socioambiental desses espaços naturais protegidos. Com efeito, esse fato requer um planejamento e gestão racional do ecoturismo evidenciando os limites dos sistemas ecológicos e socioculturais

\section{O Plano Nacional do Turismo (PNT) X SNUC: a relação com o Ecoturismo}

O ecoturismo tem despertado a preocupação de agentes de governança e da sociedade sendo esse um dos fatos que gerou a implementação do SNUC. Além disso, o governo brasileiro também criou o Plano Nacional do Turismo (2003/2007), com programas que apresentam ações que se aproximam da gestão turística em Unidades de Conservação. Dessa forma, como explica Azevedo e Soares (apud POLES; RABINOVICI, 2010):

O ecoturismo surgiu como um segmento turístico preocupado com os recursos culturais e naturais com a localidade, a participação e a uma 
série de estratégias que tencionam aumentar os impactos positivos do turismo sobre a natureza e a conservação ambiental. Por estas características o turismo é considerado como a menos impactante das alternativas econômicas nos ambientes naturais protegidos por lei, se tornando, inclusive, justificativa para a criação de UCs, em virtude da necessidade de sobrevivência dentro do sistema capitalista.

Dentro do PNT, distribuídos em 7 Macro Programas, pode-se dizer que o Macro Programa 4, o Programa de Planejamento e Gestão da Regionalização, o Programa de estruturação dos segmentos turísticos, programa de estruturação da produção associada ao turismo, programa de apoio ao desenvolvimento regional do turismo são os que mais se aproximam da gestão turística em Unidades de Conservação. Esse fato pode ser comprovado tanto pela necessidade de se ter a participação das instâncias de governança como pela necessidade de se segmentar o turismo nas diversas modalidades apresentadas pelo Programa dentre estas, o Ecoturismo (PNT, 2007, p.68). Esses Programas assimilam a noção do território como espaço e lugar de interação do homem com o ambiente, dando origem a diversas maneiras de se organizar e se relacionar com a natureza, a cultura e com os recursos de que dispõe. Pelo previsto nos Programas, as ações a serem desenvolvidas serão articuladas reconhecendo o espaço regional e a segmentação do turismo, construído e implementado pelos próprios atores públicos e privados nas diversas regiões do país, constituindo uma estratégia facilitadora do desenvolvimento territorial integrada (PNT, 2007).

Analisando as conformidades legais do SNUC e do PNT - 2003/2007 para o ecoturismo em UCs é possível perceber a visão estratégica que estes propõem aos tomadores de decisão de modo que possibilitem aos atores das UCs, além de conservar os ecossistemas e a biodiversidade, gerar renda, emprego, desenvolvimento e propiciar uma efetiva melhoria na qualidade de vida das populações locais do Brasil. Contudo, os Estados e Municípios brasileiros precisam ter condições infraestruturais, técnico-científicas, para possibilitarem a consolidação das funções socioambientais, econômicas e culturais do ecoturismo em UCs. De acordo com Monteiro e Nóbrega (2008, p.72)

O Zoneamento Ambiental e os Planos de Manejo são os principais ins-
trumentos de gestão de unidades de conservação. O Zoneamento Am-
biental estabelece uma compartimentação de um determinado territó-
rio em zonas diferenciadas de utilização do solo e dos recursos natu-
rais, considerando as questões geomorfológicas, bióticas e sociocultu-
rais. Todas as unidades de conservação devem ser gerenciadas por
um Plano de Manejo, também chamado de Plano de Gestão. Atual-
mente, esse planejamento tende a ser participativo, envolvendo a soci-
edade como um todo, especialmente as populações vizinhas e Organi-
zações - Não Governamentais - ONGs.

Assim, o Zoneamento Ambiental e os Planos de Manejo são os principais ins- 
trumentos de planejamento e gestão de UCs, inclusive para a implementação do ecoturismo nessas áreas protegidas. Segundo o Prof. Dr. Giovane de Farias Seabra ${ }^{6}$ na maioria das UCs não existe infraestrutura necessária à preservação dos ecossistemas e ao acompanhamento, acolhimento e fiscalização dos visitantes, estando sujeitas a prováveis impactos negativos do meio ambiente.

O Plano de Manejo possibilita a todos os atores sociais, instâncias governamentais e Organizações - Não Governamentais (ONGs) dialogarem acerca das potencialidades, problemas e soluções para o desenvolvimento do ecoturismo com vistas à sustentabilidade nas UCs. Nesse sentido, este Plano pode ser entendido como um instrumento de gestão participativa e que possibilita a ampliação do debate inclusivo acerca do desenvolvimento sustentável da atividade turística nas UCs. Nesse contexto, Philippi Jr. e Maglio (2004, p.221) afirmam que

os primeiros passos para a sustentabilidade nas suas várias dimensões são o planejamento e a gestão. O planejamento deve ser considerado um conjunto de ações intencionais integradas e coordenadas que visam a tornar realidade os objetivos almejados. A gestão é considerada um "processo político administrativo de responsabilidade do poder constituído que, apoiado por uma participação social, é destinado a formular, implementar e avaliar políticas ambientais a partir da cultura, realidade e potencialidades de cada região em conformidade com os princípios do desenvolvimento sustentável.

De acordo com o Programa de Monitoramento de áreas Protegidas do Instituto Socioambiental, entre as 1.034 (mil e trinta e quatro) Unidades de Conservação existentes hoje no Brasil, apenas 97 (noventa e sete) contam com conselhos gestores instâncias previstas na gestão das UCs que devem ser constituídas de forma paritária por representantes da sociedade civil, do governo e da população local, dependendo da categoria da unidade de conservação.

De acordo com (VALLEJO, 2006, p.21),

os principais problemas dos conselhos gestores são relativos à falta de meios de comunicação, à lentidão dos órgãos ambientais em repassar verbas para o funcionamento, implementação das decisões tomadas e o desinteresse dos chefes da UCs.

Nesse ínterim, observa-se que esses problemas comprometem o planejamento e a gestão participativa da atividade turística. A gestão do turismo em UCs precisa propor o ordenamento das atividades humanas nesses espaços para que estas originem o menor impacto possível sobre o meio. O artigo 225 da Constituição Federal, ao mesmo tempo em que estabelece "o meio ambiente ecologicamente equilibrado" como direito e como "bem de uso comum do povo e essencial à sadia qualidade de vida", também impõe ao "Poder Público e à coletividade o dever de defendê-lo e preser- 
Planejamento e Políticas Públicas do Turismo: uma discussão teórica no contexto das Unidades de Conservação do Brasil

vá-lo para as presentes e futuras gerações". Quintas (2006, p.30) em sua abordagem sobre Gestão ambiental define como:

O processo de mediação de interesses e conflitos (potenciais ou explícitos) entre atores sociais que agem sobre os meios físico-natural e construído, objetivando garantir o direito ao meio ambiente ecologicamente equilibrado, conforme determina a Constituição Federal.

O que deve ficar claro é que "gerir" ou "gerenciar" denota saber manejar as ferramentas existentes da melhor forma possível e não necessariamente desenvolver a técnica ou a pesquisa como parte das ciências naturais, pesquisas ambientais, sistemas e outros. Para se atingir formas de turismo mais sustentáveis e adequadas em UCs, os gestores ou gerentes precisam ter uma visão holística ${ }^{7}$ e apurada do contexto político para que seja possível compreender a estrutura dos problemas de planejamento e gestão como uma meta política em termos de realização.

\section{Considerações finais}

Na relação entre turismo e UCs, percebe-se que a atividade turística não pode ser vista como a panacéia dos males que são provocados ao espaço geográfico e a sociedade. No entanto, pode-se crer que, se esta for desenvolvida em harmonia com os sistemas socioambientais, poderá minimizar impactos potencialmente negativos, maximizar retornos econômicos nos destinos e, desta forma, estimular uma resposta mais positiva por parte da comunidade hospedeira em relação ao turismo em longo prazo.

Um melhor redimensionamento dos objetivos do Plano (PNT) direcionados ao planejamento e gestão do ecoturismo em UCs, como também a elaboração e implementação de políticas públicas direcionadas as questões de organização dos espaços, permitirá a melhoria da qualidade de vida da população local, muitas vezes desprovidas de condições dignas de sobrevivência, e a sustentabilidade do ecoturismo nessas áreas protegidas.

Por essa abordagem, cabe frisar a importância da ampliação de um debate crítico, contextualizando a manutenção do equilíbrio natural e integridade sociocultural e a intensidade da degradação dos sistemas naturais e desestabilização dos sistemas socioculturais bem como as estratégias adequadas para melhorar ou mitigar o que foi estabelecido como problema socioambiental e cultural.

\section{Referências bibliográficas}

ANSARAH, M.G.R. (Org.) Turismo Como aprender, como ensinar. SP: editora SENAC. 2001. 406 P. 
AZEVEDO. F. F.; SOARES, A.S. Construção e Conservação no Ecoturismo das UCS Área de proteção Ambiental Jenipabu e Reserva de Desenvolvimento Sustentável Estadual Ponta do Tubarão (RN): a percepção dos atores que neles atuam. Anais do VI Encontro Nacional das Anppas, 2002. Pará.

BRASIL. Grupo de Trabalho Interministerial MICT/MMA. Diretrizes para uma política nacional de Ecoturismo. Brasília: EMBRATUR, 1994.

BRASIL. Ministério do Turismo. Manual do Pesquisador - Inventário da Oferta Turística: instrumento de pesquisa/ Ministério do Turismo, Secretaria Nacional de Políticas de Turismo, Departamento de Estruturação, Articulação e Ordenamento Turístico. Brasília: Ministério do Turismo, dezembro de 2006. I. Título. II. Brasil. Secretaria Nacional de Políticas de Turismo.

CIVIDANES A.; KUTZKE C. O conhecimento do Espeleoturismo em Curitiba, Monografia. Curitiba: Unioandrade, 2003.

COELHO, R.C. Estado, governo e mercado. Florianópolis : Departamento de Ciências da Administração / UFSC; [Brasília] : CAPES : UAB, 2009. 116p. : il. Especialização - Módulo Básico

CRUZ, R.C.A. Introdução à geografia do turismo. 2. Ed. São Paulo: Roca, 2001.

CRUZ, R.C.A. Políticas de turismo e (re)ordenamento de territórios no litoral nordeste do Brasil. 1999. Tese (Doutorado em Geografia)- Faculdade de Filosofia, Letras e Ciências Humanas, Universidade de São Paulo, 1999.

DIAS, R. Planejamento do Turismo Política e Desenvolvimento do Turismo no Brasil. Atlas. 2003. SP

DIAS, R.; FIGUEIRA; V. A Responsabilidade Social no Turismo. Escolar. 2011. São Paulo.

EMBRATUR. Turismo, estruturação e legislação básica. Disponível em: http:// www.embratur.gov.br. Acesso em 10 de junho de 2013.

FIGUEIREDO, S.L. Ecoturismo, festas e rituais na Amazônia. Belém: NAEA/UFPA, 1999.

FURTADO, C. 0 mito do desenvolvimento econômico. Rio de Janeiro: Paz e Terra, 1974.

FURTADO, C. Introdução ao desenvolvimento: enfoque histórico - estrutural. Rio de Janeiro: Paz e Terra, 2000.

ISA - Instituto Soambiental. http:/www.socioambiental.org. Acesso em 11 de junho de 2013.

MCKERCHER B. A proteção do Meio Ambiente, Revista Eletrônica Label France, $\mathrm{n}^{\circ}$ 45, dezembro, 2001. 
Planejamento e Políticas Públicas do Turismo: uma discussão teórica no contexto das Unidades de Conservação do Brasil

MONTEIRO, J.S.M.; NÓBREGA, M.R.W. Gestão ambiental em unidades de conservação:refl exões e proposta acerca das instalações (eco) turísticas na Área de Proteção Ambiental Algodoal-Maiandeua, Maracanã-Pará. Caderno Virtual de Turismo, v.8, n.3, 2008.

NASCIMENTO, L.K.S. Geografia, turismo e meio ambiente: uma nova face do litoral dos municípios de Extremoz e Ceará-Mirim. Natal,RN, 2008. Dissertação (Mestrado em Geografia) - Centro de Ciências Humanas, Letras e Artes. Programa de PósGraduação e Pesquisa em Geografia. Universidade Federal do Rio Grande do Norte. $114 f$.

NUNES, P. Conceito de gestão e de gestor. mimeo, 2006.

Organização Mundial do Turismo (OMT). Turismo no mundo. Disponível em http:/ www.word-turismo.org. Acesso em 10 de junho de 2013.

PÁDUA. M.T.J. Unidades de conservação: muito mais do que atos de criação e planos de manejo. In: MILANO, M.S. Unidades de Conservação: Atualidades e Tendências. Curitiba: Fundação O Boticário de Proteção à Natureza, p.7-13.

PETROCCHI, M. O turismo é a atividade que mais distribui renda e empregos. Comércio Exterior. BB, 21, p. 16-20. 1999.

PHILIPPI JR., A.; MAGLIO, I.C. Política e Gestão Ambiental: conceitos e instrumentos. In: PHILIPPI JR., A.; PELICIONI, M.C.F. (orgs) Educação Ambiental e Sustentabilidade. Barueri, 2004 (Coleção Ambiental)

PIRES, E.; MÜLLER, G.; VERDI, A. Instituições, Territórios e Desenvolvimento Local: delineamento preliminar dos aspectos teóricos e morfológicos. Geografia - Associação de Geografia Teorética. Rio Claro, SP, v. 31, 2002.

QUINTAS, J.S. Introdução à Gestão Ambiental Pública. Edição Instituto Brasileiro do Meio Ambiente e dos Recursos Naturais Renováveis. Diretoria de Gestão Estratégica. Centro Nacional de Informação, Tecnologias Ambientais e Editora. $2^{\underline{a}}$ edição. ed. revista. - Brasília : Ibama, 2006. 134p. (Coleção Meio Ambiente. Série Educação ambiental, 5)

RODRIGUES, A.B. Turismo e Ambiente: Reflexões e propostas. $2^{\mathrm{a}}$ ed. São Paulo: Hucitec, 1999.

RUA, M.G. Políticas públicas. Florianópolis : Departamento de Ciências da Administração / UFSC; [Brasília]: CAPES : UAB, 2009.

SACHS, I. Caminhos para o desenvolvimento sustentável. Rio de Janeiro: Garamond, 2001.

SACHS, I. Caminho para o desenvolvimento sustentável. Rio de Janeiro: Garamond, 2000. 
SANTOS, M. A Natureza do Espaço: Técnica, Razão e Emoção. 4. ed. 4.reimp.São Paulo. Edusp, 2008.

SANTOS, M. Espaço e método. São Paulo: Nobel, 1985.

SANTOS, M. Por uma geografia nova. 3. Ed.São Paulo : Hucitec, 1978.

SARTOR, L.F. Introdução ao Turismo. Caxias do Sul. Universidade de Caxias de Sul: Porto Alegre, escola superior de tecnologia, São Lourenço de Brindes, 1997.

SOARES, A.S. O ecoturismo sob a égide da sociedade do consumo: um estudo das Unidades de Conservação de uso sustentável do RN. Natal, RN, 2011. Dissertação (Mestrado em Turismo) - Universidade Federal do Rio Grande do Norte. Centro de Ciências Sociais Aplicadas. Programa de Pós-Graduação em Turismo.111 f.

SISTEMA Nacional de Unidades de Conservação da Natureza - SNUC: a lei n. 9.985, de 18 de julho de 2000. Brasília: MMA/SBF, 2000, 32 p.

SWARBROOKE, J. Turismo Sustentável: conceitos e impacto ambiental. São Paulo: Aleph, 2000.

TELES, M.L.S. Educação sem fronteiras: cuidando do ser. Petrópolis, RJ. Vozes, 2003.

UICN/PNUMA/WWF. Estratégia mundial para a conservação, CESP: São Paulo, 1980.

VALLEJO. R.L. Unidades de Conservação: Uma discussão teórica à luz dos conceitos de território e de políticas públicas. Mimeo. Universidade Federal Fluminense. 2006.

\section{Notas}

1 [...] entendido como a conjugação entre os sistemas de objetos e os sistemas de ações (SANTOS, 1999, p. 51).

2 Os objetos são tudo o que existe na superfície da Terra, toda herança da história natural e todo resultado da ação humana (SANTOS, 2006).

${ }^{3}$ Entende-se por equipamentos turísticos, o conjunto de elementos, ou objetos inseridos no espaço que serão responsáveis pela dinamização da atividade turística, podemos citar como exemplo: hotéis, pousadas, equipamentos de lazer, restaurantes e outros (BRASIL, 2006, p.10)..

${ }^{4}$ A Sociedade é um conjunto de indivíduos, dotados de interesses e recursos de poder diferenciados, que interagem continuamente a fim de satisfazer às suas necessidades (RUA, 2009, p. 14). 
5 Políticas Públicas são diretrizes, princípios norteadores de ação do poder público; regras e procedimentos para as relações entre poder público e sociedade, mediações entre atores da sociedade e do Estado. São, nesse caso, políticas explicitadas, sistematizadas ou formuladas em documentos (Leis, programas, linhas de financiamentos) que orientam ações que

normalmente envolvem aplicações de recursos públicos (TEIXEIRA, 2002, p. 2)

${ }^{6}$ Tal afirmativa encontra-se no artigo "Planejamento e gestão em unidades de conservação: comunidade, visitantes e preservação ambiental".

${ }^{7}$ Holos, palavra grega, significa todo, totalidade (Holístico).(TELES, 2003, p. 50).

Iracy Wanderley Filha: Universidade Federal do Rio Grande do Norte, Natal, RN, Brasil E-Mail: ciciea.wf@gmail.com

Link para o currículo Lattes: http://lattes.cnpq.br/5372082985640197

Francisco Fransualdo de Azevedo: Universidade Federal do Rio Grande do Norte, Natal, RN, Brasil

E-Mail: ffazevedo@gmail.com

Link para o currículo Lattes: http://lattes.cnpq.br/2719998085102847

Wilker Ricardo de Mendonça Nóbrega: Universidade Federal do Rio Grande do Norte, Natal, RN, Brasil

E-Mail: wilkernobrega@yahoo.com.br

Link para o currículo Lattes: http://lattes.cnpq.br/0025142529544906

Jaci Câmara de Albuquerque: Instituto Federal de Educação Ciência e Tecnologia do Tocantins, Palmas, TO, Brasil

E-Mail: jaci@ifto.edu.br

Link para o currículo Lattes: http://lattes.cnpq.br/3942151441935777

Data de submissão: 29 de julho de 2013

Data de recebimento de correções: 29 de julho de 2013

Data do aceite: 25 de outubro de 2013

Avaliado anonimamente 